\title{
Geo-electrical Resistivity Survey in the High Barind for the Delineation of Aquifer Geometry
}

\author{
A.H.M.Selim Reza ${ }^{1}$, Quamrul Hasan Mazumder ${ }^{1}$ and Mushfique Ahmed ${ }^{1}$ \\ ${ }^{1}$ Departmetnt of Geology and Mining, University of Rajshahi, \\ Rajshahi-6205, Bangladesh
}

\begin{abstract}
Geo-electrical resistivity techniques have been employed in the High Barind as a reconnaissance investigation for the subsurface lithology. Out of 13 upazillas, comprising the Barind tract, Sapahar and Porsha Upazillas, situated in the High Barind are badly affected by water shortage. Vertical electrical soundings (VES) were executed using Schlumberger configuration in different areas taking the current electrode separation up to 170 meters. Direct method technique was employed to evaluate the geoelectric layer such as resistivity and thickness of the discrete layers. The results of the resistivity survey give the subsurface information consisting of three to four layers. The results of geo-electric sounding have been compared with the geological section wherever available.
\end{abstract}

\section{Introduction}

Geophysical methods provide useful information on subsurface geological structure and lithology. With the advancement of technology different methods have been developed for exploration work. Among the others the electrical method [1] is much more effective for shallow exploration giving information on subsurface features. Electrical method studies the electrical properties of the earth and distinguishes different types of material.

In resistivity method vertical electric sounding (VES) [2] is one kind of measurement in which a succession of apparent resitivity is recorded with an increasing electrode separation, the center of the configuration and its orientation remaining fixed. Electrical resistivity survey is very effective method for characterizing aquifer in terms of more resistive from the less resistive. In view of the geological conditions and available geophysical information on the area an electrical resistivity survey has been carried out in the High Barind. Twelve vertical soundings were conducted in the area. Institute of Water Modeling (IWM) carried out a detailed geophysical survey for groundwater resources study and decision support system development of Thakurgaon, Panchagarh, Dinajpur, Joypurhat districts and also remaining districts of Rajshahi Division through mathematical model study under Barind Multipurpose Development Authority (BMDA). 


\section{Location and Extent}

The study area lies between $24^{\circ} 54^{\prime} \mathrm{N}$ and $25^{\circ} 13^{\prime} \mathrm{N}$ latitudes and $88^{\circ} 23^{\prime} \mathrm{E}$ and $88^{\circ} 39^{\prime}$ E longitudes. It comprises a total area of $497.3 \mathrm{sq} \mathrm{km}$. The resistivity survey has been carried out at twelve different stations as shown in fig.1.

\section{Geology}

The study area lies within the High Barind. This is the uplifted part of the Barind tract. It was formed by the deposition of sediments carried by the river Ganges and the Brahmaputra and their tributaries in the Pleistocene age [3]. This alluvium is composed of mostly clay, silt and fine sand. The Pleistocene sediments are well- oxidized and typically reddish, brown or tan. They commonly contain ferruginous or calcareous nodules, which were deposited by the Ganges- Brahmaputra fluvial system. Water content is low due to firm and compact materials.

\section{Hydrogeology}

Hydrogeological cross section has been constructed along NS directions of the study area (Fig.2). According to the lithological constituents and on the basis of hydrogeological types, the subsurface layers are divided into three zones.

Zone 1: The zone extends vertically up to an average depth of 6 to $36 \mathrm{~m}$ below ground surface and is composed mainly of clay with occasional fine sand and silt. Zone 2: The thickness of this thin zone varies from 15 to51 m and is mainly composed of fine, medium and coarse sand with gravel.

Zone 3: in some part of the study area, there is another silty shale sequence below zone 2 ranging in thickness of about 2 to $17 \mathrm{~m}$.

\section{Data Acquisition and Processing}

The area of the investigation was covered by sounding surveys. Vertical electrical soundings (VES) have been executed using Schlumberger electrode configuration taking the current electrode separation up to $170 \mathrm{~m}$. Twelve soundings were made (Fig.1). Each location is assigned an individual VES number such as VES 1, VES 2, VES 3, VES 4, VES 5, VES 6, VES 7, VES 8, VES 9, VES 10, VES 11 and VES 12. Resistivity values with respect to distance were recorded for each sounding point. The resistivity data are plotted from sounding data. Interpretation of these sounding curves is done by using USGS software programme [5]. The DD resistivity meter was used in the field. 


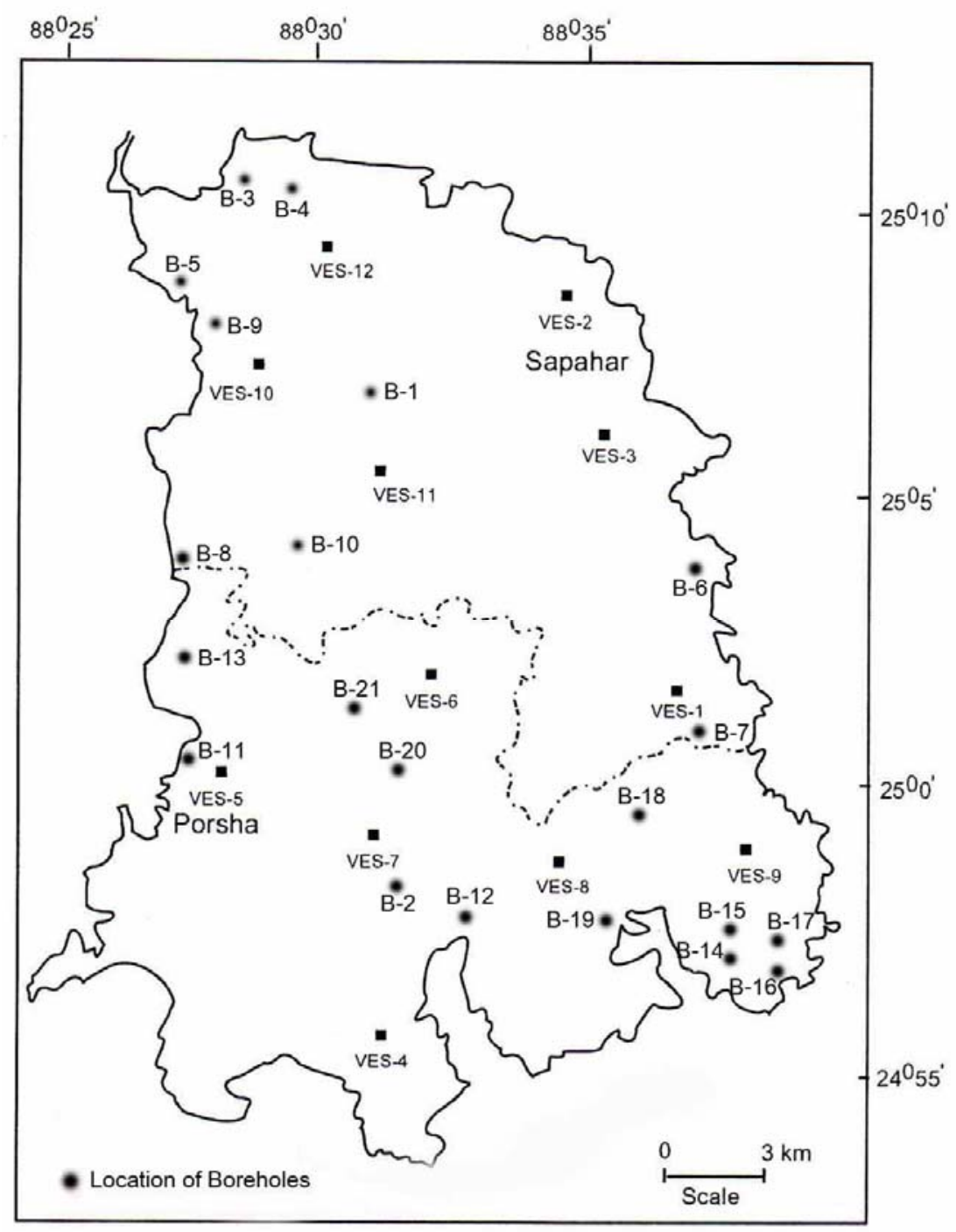

Fig.1. Location map of the study area showing the location of VES points and boreholes 


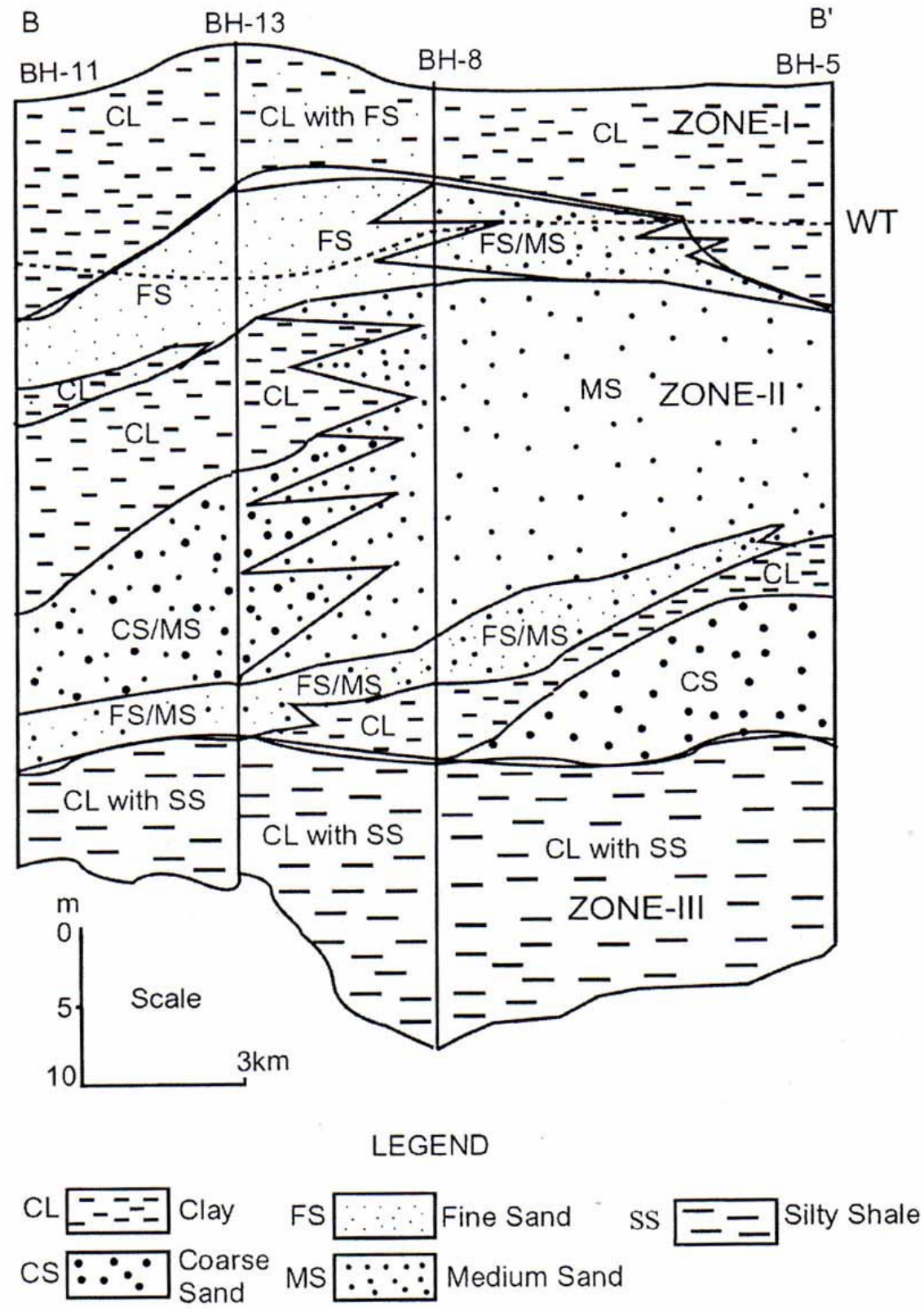

Fig.2. Cross section along NS direction 


\section{Basic Principles of Electrical Resistivity Method}

The basic principles of electrical resistivity method is to send current into the ground y means of two electrodes and the potential difference between two other electrodes is measured in time. From the magnitude of potential difference and current and knowledge of the electrode separation a quantity known as the apparent resistivity can be calculated. For a quantitative treatment, let us consider a homogeneous isotropic earth layer of resistivity $\rho$, legth $L$, resistance $R$ and cross sectional area A, through which a Current I is following:

$$
\mathrm{V}=\rho \mathrm{I} / 2 \pi \mathrm{r}
$$

This is the basic equation, which enables the calculation of the potential distribution in a homogeneous conducting medium. In the above equation $r$ is the geometric factor, which is different electrode configuration. Fig. 3 shows the distribution of the potential and the lines of current flow in the vertical section of a homogeneous conducting underground medium due to a pair of current electrodes [4].

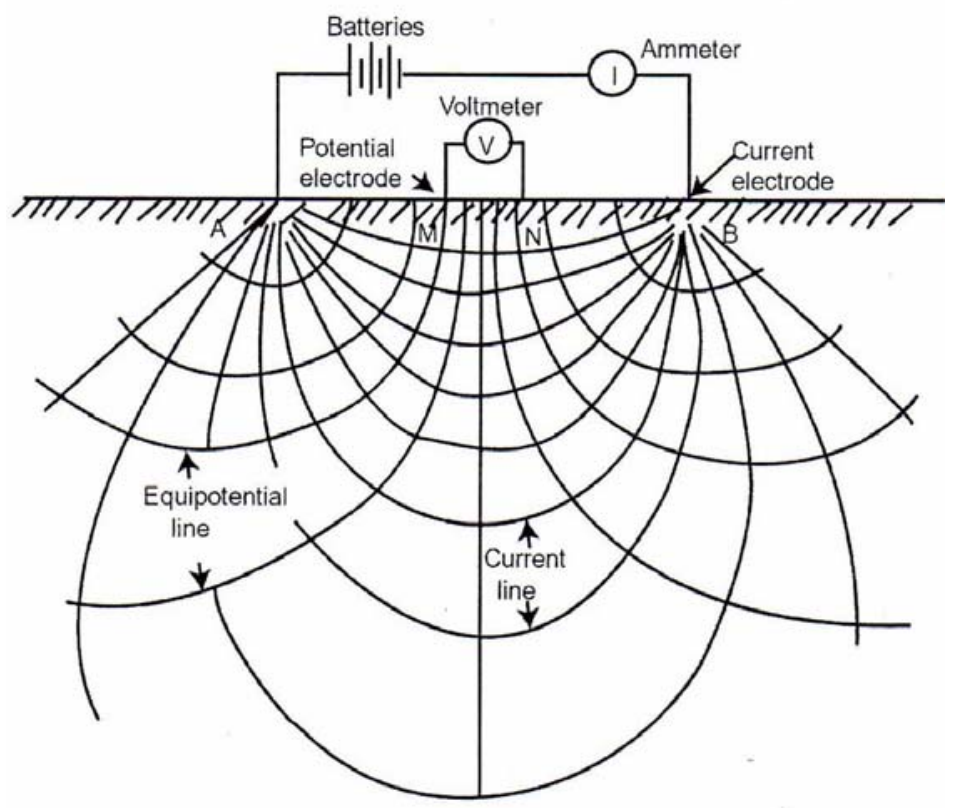

Fig.3. Distribution of the potential and the lines of current flow 


\section{Data Acquisition and Processing}

The area of the investigation was covered by sounding surveys. Vertical electrical soundings (VES) have been executed using Schlumberger electrode configuration taking the current electrode separation up to $170 \mathrm{~m}$. Twelve soundings were made (Fig.1). Each location is assigned an individual VES number such as VES 1, VES 2, VES 3, VES 4, VES 5, VES 6, VES 7, VES 8, VES 9, VES 10, VES 11 and VES 12. Resistivity values with respect to distance were recorded for each sounding point. The resistivity data are plotted from sounding data. Interpretation of these sounding curves is done by using USGS software programme [5]. The DD resistivity meter was used in the field.

\section{Result and Interpretation}

The field data obtained in the form of an apparent resistivity curve $\left(\rho_{a}\right)$ is interpreted in terms of basis theory and the results are then correlated with the available hydrogeological information to arrive at a realistic picture of subsurface structure. The field data were interpreted by direct method [5]. In this iterative procedure a layering model is obtained directly from digitized sounding curves. In the present study (Fig.4 to Fig.5) 12 VES curves were labeled and represented 3 and 4 layer case. Among 11 are 4 layers and 1 is three layers. The layer parameters are presented in Table-1, Interpreted field curves are shown in Figs.4 to 5 .

\section{Discussion and Conclusion}

Electrical resistivity method can be successfully employed for shallow subsurface investigation, because of the existence of good electrical resistivity contrast between different types of rock such as clay, silt, sand, gravel and other hard rocks. The results of the resistivity survey give the subsurface information consisting of three to four layers. Ranges of resistivity values are 10 to $270 \mathrm{ohm}-$ $\mathrm{m}$. Correlation between the layering of the sounding data interpretation and geology agrees. A comparison of the results with the known geological sequence suggests that the layer showing high resistivity range from 46 to $270 \mathrm{ohm}-\mathrm{m}$ could be correlated with aquifer. After the determination of the thickness and resistivities of the geo-electric layers comprising the total geo-electric column from VES curve the thickness are used to construct isopach maps of the specific geo-electric layers. These maps provide information about the lateral variation of thickness of specific geo-electric layers, which resemble to specific geological formations. On the basis of hydrogeological ehaviors, interpreted geo-electrical layers are grouped into two forms, aquitard and aquifer. The first layer of top sandy and silty clay and in some cases, second and third layers if critically analyzed from hydrogeological point of view, may be considered as aquitard and the rest of the layers, which are mainly composed of sandy formations, can be 
considered as the only aquifer present in the study area. In connection with Groundwater Resource study and Decision Support System Development of Thakurgaon, Panchagar, Dinajpur, Joypurhat Districts through Mathematical Model (Deep Tubeweel Installation Programme Unit-2), Geological Department Dhaka University under subcontract with IWM carried out geophysical resistivity and shallow seismic survey during 2009 in Panchagar, Dinajpur and Joypurhat areas [6]. The gist of the investigation and study indicate the lithological distribution up to depth of $300 \mathrm{~m}$ in Panchagar district. Three layers viz. 1 to $4 \mathrm{~m}$ depth clay, silt and fine sand layer at the top, which are under lined by layers of sand with gravels up to the depth of $300 \mathrm{~m}$. Fine and fine to medium intrudes in between the medium and coarse sandy layer [6].

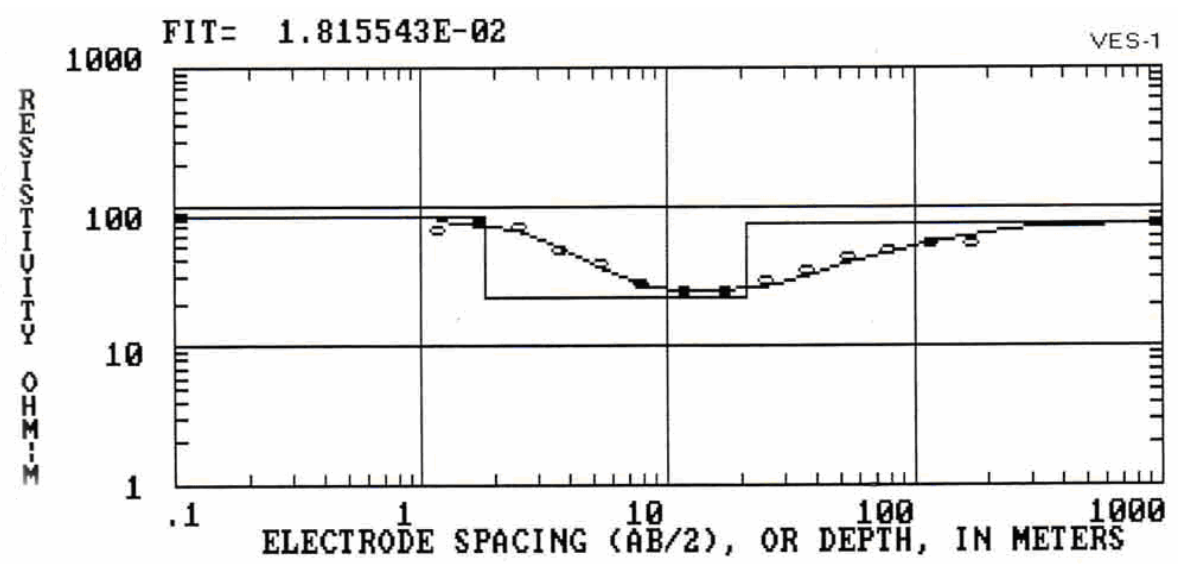

Fig.4. Sounding curve and interpretation of VES

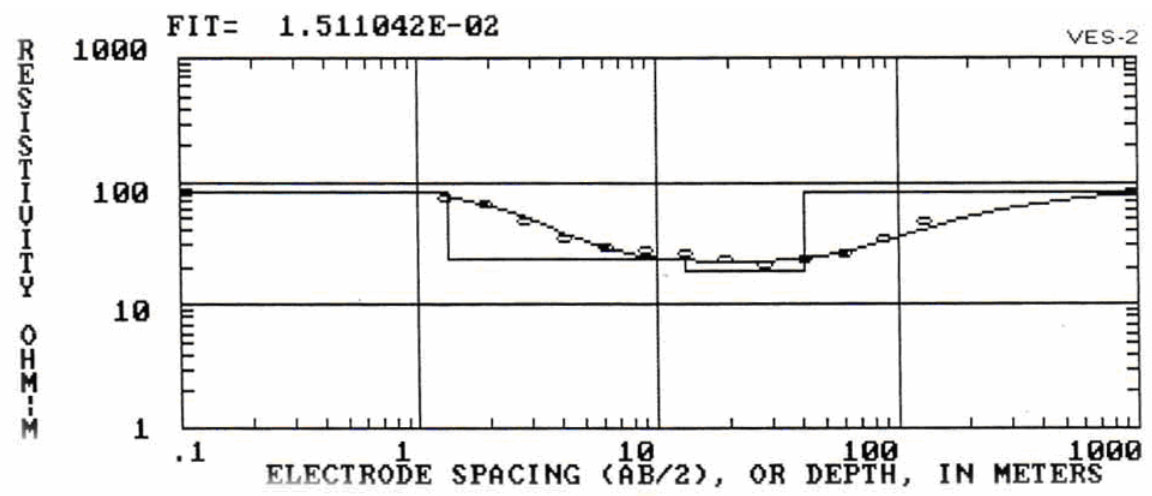

Fig. 5. Sounding curve and interpretation of VES 
Table1. The interpreted layer parameter of the sounding curves.

** Denotes undetermined

\begin{tabular}{|c|c|c|c|c|}
\hline VES Stations & $\begin{array}{l}\text { Layer } \\
\text { Number }\end{array}$ & $\begin{array}{l}\text { Depth to the } \\
\text { layer }\end{array}$ & $\begin{array}{l}\text { Thickness of } \\
\text { the layer (m) }\end{array}$ & $\begin{array}{l}\text { Resistivity of } \\
\text { the layer } \\
\text { (ohm-m) }\end{array}$ \\
\hline \multirow{3}{*}{ VES 1} & 1 & 1.8 & 1.8 & 85 \\
\hline & 2 & 21 & 19.2 & 22 \\
\hline & 3 & $* *$ & $* *$ & 75 \\
\hline \multirow{4}{*}{ VES 2} & 1 & 1.32 & 1.32 & 85 \\
\hline & 2 & 13 & 11.68 & 23 \\
\hline & 3 & 41 & 28 & 19 \\
\hline & 4 & $* *$ & $* *$ & 85 \\
\hline \multirow{4}{*}{ VES 3} & 1 & 1.52 & 1.52 & 56 \\
\hline & 2 & 10 & 8.48 & 25 \\
\hline & 3 & 37 & 27 & 70 \\
\hline & 4 & $* *$ & $* *$ & 12 \\
\hline \multirow{4}{*}{ VES 4} & 1 & 0.4 & 0.4 & 143 \\
\hline & 2 & 6.5 & 6.1 & 27 \\
\hline & 3 & 58 & 51.5 & 120 \\
\hline & 4 & $* *$ & $* *$ & 30 \\
\hline \multirow{4}{*}{ VES 5} & 1 & 1.32 & 1.32 & 70 \\
\hline & 2 & 3.5 & 2.18 & 15 \\
\hline & 3 & 16.8 & 13.3 & 10 \\
\hline & 4 & $* *$ & $* *$ & 50 \\
\hline \multirow{4}{*}{ VES 6} & 1 & 1.02 & 1.02 & 69 \\
\hline & 2 & 4.8 & 3.78 & 30 \\
\hline & 3 & 44 & 39.2 & 270 \\
\hline & 4 & $* *$ & $* *$ & 18 \\
\hline \multirow{4}{*}{ VES 7} & 1 & 0.6 & 0.6 & 100 \\
\hline & 2 & 4 & 3.4 & 20 \\
\hline & 3 & 45 & 41 & 106 \\
\hline & 4 & $* *$ & $* *$ & 10 \\
\hline \multirow{4}{*}{ VES 8} & 1 & 1 & 1 & 85 \\
\hline & 2 & 4 & 3 & 13 \\
\hline & 3 & 40 & 36 & 80 \\
\hline & 4 & $* *$ & $* *$ & 30 \\
\hline \multirow{4}{*}{ VES 9} & 1 & 1 & 1 & 78 \\
\hline & 2 & 5 & 4 & 34 \\
\hline & 3 & 54 & 49 & 205 \\
\hline & 4 & $* *$ & $* *$ & 25 \\
\hline
\end{tabular}




\begin{tabular}{|c|c|c|c|c|}
\hline \multirow{4}{*}{ VES 10 } & 1 & 1.5 & 1.5 & 90 \\
\cline { 2 - 5 } & 2 & 12 & 10.5 & 22 \\
\cline { 2 - 5 } & 3 & 37 & 25 & 46 \\
\cline { 2 - 5 } & 4 & $* *$ & $* *$ & 16 \\
\hline \multirow{3}{*}{ VES 11 } & 1 & 1 & 1 & 75 \\
\cline { 2 - 5 } & 2 & 12 & 11 & 35 \\
\cline { 2 - 5 } & 3 & 38 & 26 & 70 \\
\hline \multirow{3}{*}{ VES 12 } & 4 & $* *$ & $* *$ & 25 \\
\cline { 2 - 5 } & 1 & 1.01 & 1.01 & 80 \\
\cline { 2 - 5 } & 2 & 4 & 2.99 & 30 \\
\cline { 2 - 5 } & 4 & 25 & 21 & 18 \\
\hline
\end{tabular}

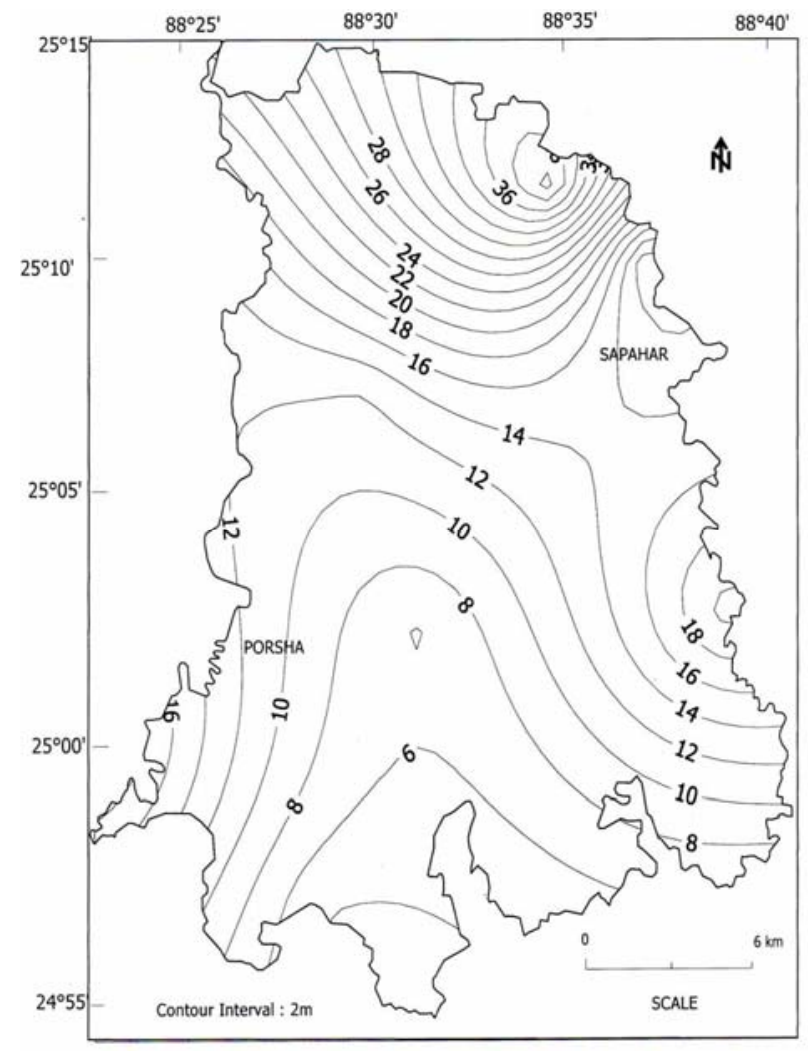

Fig. 6. Thickness map of top clay layer 
For the present study two isopach maps have been prepared for the aquitard and aquifer, which is represented in figs. 6 and 7. The thickness of the top sandy and silty clay layer varies from 4 to $41 \mathrm{~m}$. The highest thickness is observed at Shironti of Sapahar Upazilla and the lowest thickness is observed in the southern portion of the area. Overall the thickness of the top sandy and silty clay layer is higher in northwestern part of Sapahar Upazilla and lower in other parts of the study area. The thickness of the aquifer varies from 25 to $51.5 \mathrm{~m}$. The highest thickness $(51.5 \mathrm{~m})$ is observed at Khatirpur station of Porsha Upazilla and the lowest thickness $(25 \mathrm{~m})$ is observed in the Karmudanga of Sapahar Upazilla. Overall the thickness of aquifer is high in Porsha Upazilla. Considering the thickness of aquifer it is ascertained that the aquifers of Porsha Upazilla show better potentiality as compared to Sapahar Upazilla.

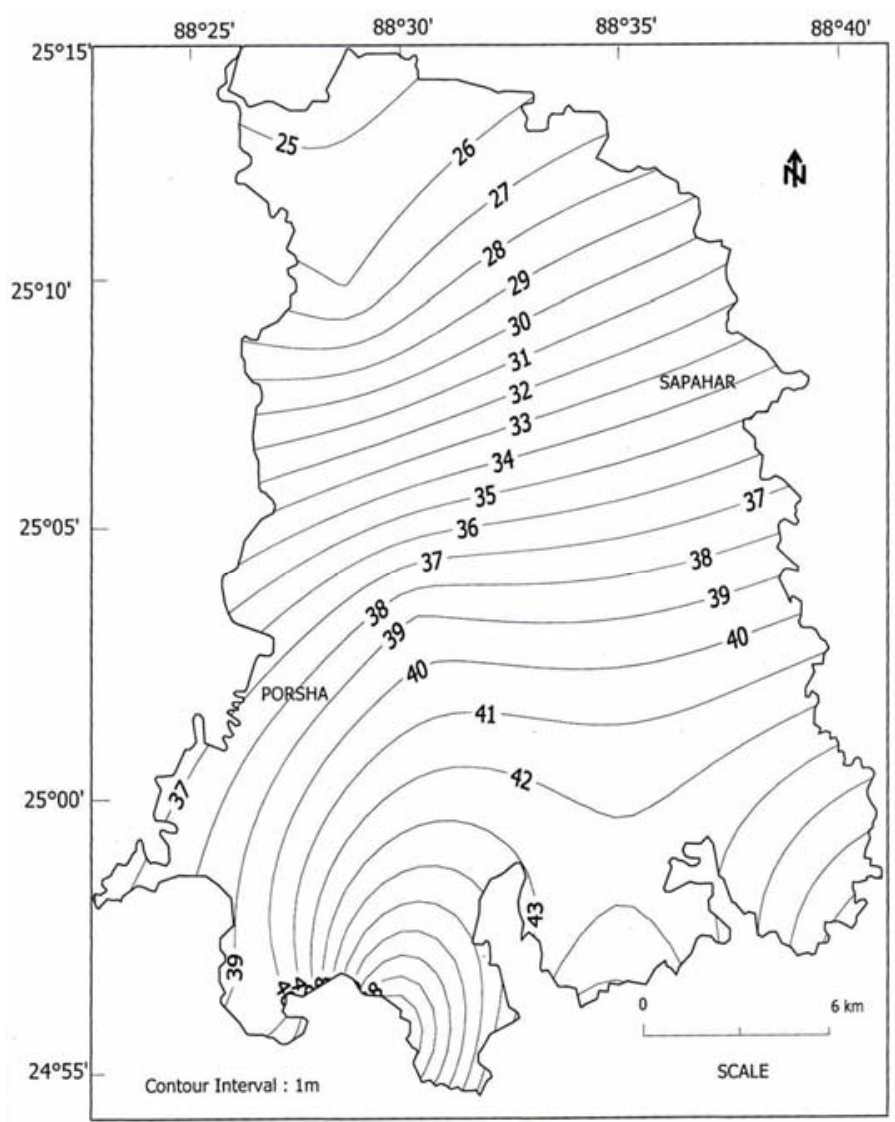

Fig.7. Thickness map of aquifer 


\section{References}

1. Keller, G.V., and Frischknecht, F.C., 1982, Electrical Methods in Geophysical Prospecting, Pergamon Press, New York.

2. Kunetz, G., 1966, Principles of Direct Current Resistivity Prospecting, Exploration Monographs series. 1, p. 103.

3. Morgan, J.P., and Mclntyre, W.G., 1959, Quaternary Geology of the Bengal Basin, East Pakistan and India, Bull, Geol. Soc.Am., v. 70, p. 319342.

4. Sharma P.V. 1978, Geophysical Method in Geology. Elsevier scientific Publishing Company, New York, p. 428.

5. Zoddy, A.A.R., 1989, A New Method for the Automatic Interpretation of Schulumberger and Wenner Sounding Curves. Geophysices, v 54, n.2. p. 245-253.

6. IWM, 2009, Groundwater Resources Study and Decision Support System Development of Thakurgaon, Panchagarh, Dinajpur, Joypurhat Districts and also Remaining Districts of Rajshahi Division Through Mathematical Model Study. Deep Tube Well Installation Programme Unit-2, Thakurgaon. Final Report. Volume-IV. 